\title{
Design of an RLC Compensator for a Synchronous Motor: Torque Ripple Improvement
}

\author{
Bashar A. Fadheel ${ }^{a *}$ \\ ${ }^{a}$ Department of Biomedical Engineering, College of Engineering, University of Kerbala.
}

\begin{tabular}{l} 
A R T I C L E I N F O \\
\hline Article history: \\
Received 05 January 2019 \\
Received in revised form 15 \\
Accepted 30 March 2019 \\
\hline Keywords: \\
AC-drive system \\
PMSM \\
Torque ripple improvement \\
RLC compensator \\
AC-DC converter \\
Speed control
\end{tabular}

A R T I CLE INFO

Article history:

Received in revised form 15 March 2019

Speed control

\begin{abstract}
A B S T R A C T
AC-drive systems based Permanent Magnet Synchronous Motor (PMSM) are widely utilized in industrial applications due to many advantages including excellent efficiency, best reliability, and low-effective cost compared with DC-drive systems. Design and implementation of an RLC compensator for a PMSM-drive system is demonstrated in this paper. The main aims of using an RLC compensator are decreasing of TotalHarmonics-Distortion (THD) of the input line current and Ripple Factor (RF) of the electromagnetic torque over a wide range variation in rotor speed and load. The entire transfer function of the proposed system is derived for stability verification under the change of rotor speeds. The proposed PMSM-drive system is implemented with and without RLC compensator for two cases; which are at a fixed load and a step-change in load. Good performance is achieved using the proposed RLC compensator; in terms of THD and RF are $0.77 \%$ and $3.13 \%$, respectively.
\end{abstract}

\section{Introduction}

AC-drive systems are essential for industrial and home utilizations due to (i) satisfying reliability, (ii) excellent efficiency and (ii) low maintenance cost compared to DC drives and AC drives based induction motors. In spite of these numerous advantages, PMSM-drive systems have, minor drawback related to increasing ripple in electromagnetic torque. The variations in rotor speed are increasing ripple in torque, which should be decreased by using adequate techniques [1]. In [2], a comparison between three control techniques has been demonstrated that related to chattering reduction for a speed controller. In [3], a hybrid space-vector based on Pulse Width Modulation (PWM) technique has been represented for minimizing the ripple in electromagnetic torque for a PMSM-drive system based on different switching topologies. Basically, the ripple in electromagnetic torque of a PMSM-drive system causes mechanical stresses. In that paper, an accurate speed controller has been implemented to minimize mechanical vibrations and noise [4]. For electric vehicles, high torque with a wide speed range is required. Few disadvantages in PMSM-drive systems, such as cogging reluctance torque which causes ripples in torque [5].Typical FieldOriented Control (FOC) for PMSM-drive systems based on dynamic mathematical equations, so the variations of parameters (e.g. electromagnetic interface, distorted flux and harmonics in the line currents), lead to low performance. In addition these drawbacks cause: oscillations in speed, ripples in torque, distortions in line currents consequently increasing THD [6].

The cause of increasing ripple in torque is due to the trapezoidal wave form of the flux around the air-gap and variable mutual reluctance due to the shape of stator slots [7]. The market of PMSM-drive systems is growing

* Corresponding author. Tel.: +964-07714856361.

E-mail address: bashar.a@uokerbala.edu.iq (Bashar A. Fadheel). 
because of low cost and high reliability. These drive systems have conventional utillizations for fast dynamic position drives and machine manipulation shaft drives, due to their torque-to-losses ratios, the effects of ripple in torque that decay the machine lifespan and position path especially at high-speeds, the noises and losses are increased [8]. In [9], a dead time compensation strategy has been proposed to mitigate the motor torque ripple for an $80 \mathrm{~kW}$ PMSM. In that paper, RF has been reduced from $30.3 \%$ to $22.3 \%$. In [5], the vibration caused in a driver was analyzed for a PMSM. It was obtained that in low speeds, the drive system is sensitive to torque ripple which was $10 \mathrm{~N} . \mathrm{m}$ without any compensator system. In [10], a developed method based on a dead-beat region between conduction and natural commutation zones has been presented for the torque-ripple reduction in a PMSM-drive system. The input signals of the controller were back-emf and the change of the back-emf during the commutation period. In [11], a developed integrated dual-output converter including switch selector has been proposed for reducing ripples in torque during a commutation period. Good performance has been achieved compared with a conventional converter. In addition, the ripples in torque during the commutation period have been improved in [12] by optimizing the currentloop controller of a PMSM-drive system. It was illustrated in [13] that the optimizing of the reluctance torque to a minimum value is not adequate to get low ripples in torque. In [14], an adaptive controller based on selfcommissioning was proposed for a PMSM-drive system according to ripples reduction in torque. A torque predictive controller based on the improved voltage vector controller has been experimentally implemented in [15] for torque-ripple minimizing. Also, in [16], the design of a PMSM has been improved based on rotor permanent-magnets skewing angle for decreasing the ripples in torque. Improved field-reconstruction controller has been represented in [17] for minimizing the ripples in torque for a PMSM-drive system which causes many problems; such as vibration during operation and increasing harmonics in back-emf.

In this paper, an RLC compensator is designed for a PMSM-drive system based synchronous motor to achieve minimum ripples in electromagnetic torque by improving THD of the input line current. The design is based on optimally matching between RLC compensator and a PMSM under the variations of rotor speeds and mechanical torque. The entire transfer function of the drive system is derived for stability analysis. The simulation results show the high performance using RLC compensator in a wide range of rotor speeds (500-1500) rpm. The scheme of the PMSM-drive system studied in this paper is shown in Fig.1. including a PMSM, a three-phase inverter, and an RLC compensator.

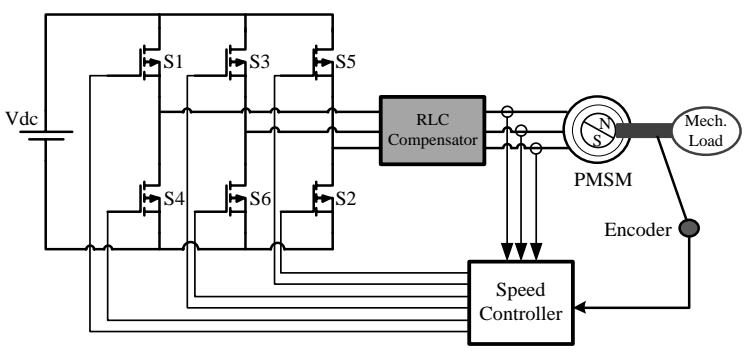

Figure 1. The proposed PMSM-drive system

\section{Modelling of a PMSM and speed controller}

\subsection{PMSM Model}

The dynamic equations of a PMSM (surface mounted type) in the threephase abc domain can be represented as below [18]. $v_{a s}(t)=R_{s} i_{a}(t)+\frac{d \psi_{a}(t)}{d t}$

$v_{b s}(t)=R_{s} i_{b}(t)+\frac{d \psi_{b}(t)}{d t}$

$v_{c s}(t)=R_{s} i_{c}(t)+\frac{d \psi_{c}(t)}{d t}$

where $R_{\mathrm{s}}$ is the stator winding resistance; $i_{\mathrm{a}}(\mathrm{t}), i_{\mathrm{b}}(\mathrm{t})$ and $i_{\mathrm{c}}(\mathrm{t})$ are the abc stator currents, respectively; $v_{\text {as }}(\mathrm{t}), v_{\mathrm{bs}}(\mathrm{t})$ and $v_{\mathrm{cs}}(\mathrm{t})$ are the abc stator voltages, respectively and $\psi_{\mathrm{a}}(\mathrm{t}), \psi_{\mathrm{b}}(\mathrm{t})$ and $\psi_{\mathrm{c}}(\mathrm{t})$ are the abc stator fluxes, respectively. However, the stator fluxes are the resultant of the flux produces from stator windings and the flux of rotor permanent magnets. Thus, stator fluxes can be presented in the rotating-reference frame as follows:

$\left[\psi_{a, b, c}(t)\right]=\left[\begin{array}{ccc}L_{s l} & M & M \\ M & L_{s l} & M \\ M & M & L_{s l}\end{array}\right]\left[i_{a, b, c}(t)\right]+\lambda_{m}\left[\begin{array}{c}\sin \left(\theta_{r}\right) \\ \sin \left(\theta_{r}-2 \pi / 3\right) \\ \sin \left(\theta_{r}+2 \pi / 3\right)\end{array}\right]$

$\mathrm{T}_{e}(t)-\mathrm{T}_{l}(t)=J_{m} \frac{d \omega(t)}{d t}+B_{m} \omega(t)$

where $L_{\mathrm{sl}}$ and $M$ are the self-inductance and the mutual-inductance of the stator windings, respectively; $\lambda_{\mathrm{m}}$ is a permanent magnetic flux of magnets on the rotor; $\theta_{\mathrm{r}}$ is the electrical position of the rotor; $J_{\mathrm{m}}$ is the rotor moment of inertia; $B_{\mathrm{m}}$ is the friction coefficient; $T_{\mathrm{e}}$ is electromagnetic torque; $T_{1}$ is load torque; $\omega_{\mathrm{e}}$ is the electrical angular velocity; $\omega(\mathrm{t})$ is rotor speed. The purpose of using a three-phase abc model is to optimally design an $R L C$ compensator for depressing THD of input line current as minimum as possible and consequently reducing the torque-ripple.

To the design an $R L C$ compensator for an AC-drive system, the phasor diagram of a PMSM can be represented as an RLE series circuit in Fig. 2. The total stator impedance $Z_{\mathrm{s}}$ includes $R_{\mathrm{s}}$ and $L_{\mathrm{s}}$ (where $L_{\mathrm{s}}$ is the equivalent stator inductance); rotor back-EMF $(E)$ is equivalent to $\left(\lambda_{\mathrm{m}} \omega_{\mathrm{r}}\right)$, which varies with rotor speeds.

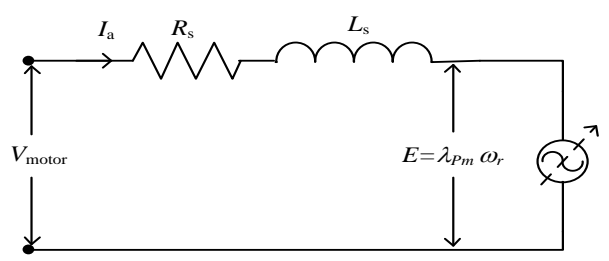

Figure 2. An equivalent circuit of a PMSM per phase

\subsection{Speed Controller in dq Frame}

In this paper, the standard vector control based on dq frame is considered for adjusting the rotor speed of the PMSM in order to investigate the relationship between the change of rotor speed and the ripples in torque. The basic dq equations are illustrated as follows:[6,19]

$$
\begin{aligned}
& v_{d}=R_{s} i_{d}+L_{d} \frac{d i_{d}}{d t}-\omega_{e} L_{q} i_{q} \\
& v_{q}=R_{s} i_{q}+L_{q} \frac{d i_{q}}{d t}+\omega_{e} L_{d} i_{d}+\omega_{e} \lambda_{m} \\
& \mathrm{~T}_{e}=\frac{3 p}{2}\left[\lambda_{m} i_{q}-\left(L_{d}-L_{q}\right) i_{d} i_{q}\right] \\
& T_{e}=1.5 p \lambda_{m} i_{q}
\end{aligned}
$$

where the parameters and variables of above equations can be represented as follows: $p$ is the number of pole-pairs; $L_{\mathrm{d}}$ and $L_{\mathrm{q}}$ are the $d$-axis and $q$ axis stator inductances, respectively; $i_{\mathrm{d}}$ and $i_{\mathrm{q}}$ are the $d$-axis and $q$-axis domain stator currents, respectively. Fig. 3 illustrates the block diagram of the speed controller used with the proposed $R L C$ compensator. It is 
based vector speed control strategy. The measured three-phase line currents are compared with the three-phase reference line currents, then adjusted by a PI controller for generating pulses to the inverter via a logical controller. The outer loop of speed controller (i.e. the difference between the reference speed $\omega_{\mathrm{r}}^{*}$ and the measured rotor speed $\omega_{\mathrm{r}}$ ) is designed to generate the reference current controller. It can be seen that the reference $d$-axis current is considered zero in order to reduce the copper losses. Also, the electromagnetic torque will include only the effective torque $\left(3 p / 2 \lambda_{m} i_{q}\right)$ and the reluctance torque (3p/2( $\left.\left.L_{d}-L_{q}\right) i_{d} i_{q}\right)$ will be zero.

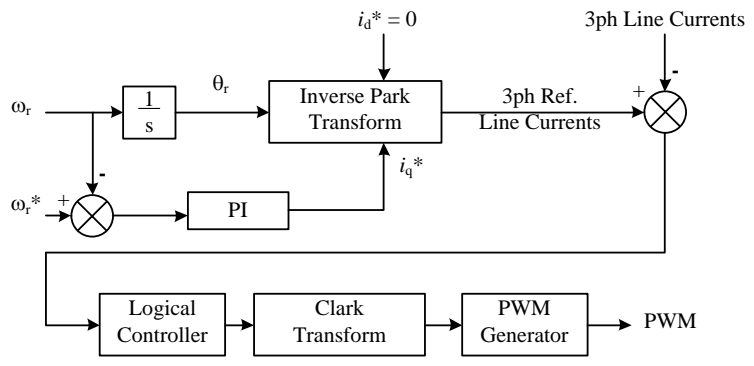

Figure 3. Block diagram of the speed controller

\section{Design and Analysis of an RLC Compensator}

\subsection{Design of RLC compensator Procedures}

The main objective of this paper is designing an $R L C$ compensator for a PMSM-drive system. In [20] and [21], an $R L C$ compensator has been proposed for decreasing $T H D$ of input current and $R F$ of electromagnetic torque. The $R L C$ compensator provides complexities in selecting its parameters that ensure stable operation of a PMSM-drive system under the variations of rotor speed and load. Basically, an $R L C$ compensator is essential for mitigation a range of frequencies (from the lower cut-off frequency $\omega_{1}$ to the upper cut-off frequency $\omega_{2}$ ). The bandwidth $B$ of the $R L C$ compensator must be related to the high switching frequency of the inverter in order to compensate the input reactive power delivered to PMSM. The function of the $R L C$ compensator is to reduce the high order harmonics of the input current at the switching frequency of the voltage source inverter (VSI), Fig. 4 shows the equivalent single line diagram of the proposed $R L C$ compensator considering the higher terms of harmonics in the line current of PMSM. Where $V_{\text {inv }}$ is the voltage supplied by a VSI; $i_{\text {inv }}$ is the input line current including harmonics; $L C$ is inductor and capacitor in series; $i_{\mathrm{Rn}}$ is the current $\mathrm{n}$-harmonic components after compensation; $i_{\mathrm{mn}}$ is the motor line current with reduced n-harmonic components and $V_{\mathrm{m}}$ phase voltage of the motor. It is worth noting that design of the proposed $R L C$ compensator is based on selecting its resonant frequency less than $50 \%$ of the switching frequency of the VSI in order to avoid resonance drawbacks.[22]. The optimal values of $R, L$, and $C$ of the compensator are calculated to obtain the best performance [23, 24]. It is worth noting that the reactive power $Q$ is calculated at full-load.

$$
\begin{aligned}
& R_{f}=B \sqrt{\frac{L_{f}}{\omega_{1} \omega_{2} C_{f}}} \\
& L_{f}=\frac{1}{\omega_{1} \omega_{2} C_{f}} \\
& C_{f}=\frac{Q}{\sqrt{\omega_{1} \omega_{2} V}}
\end{aligned}
$$

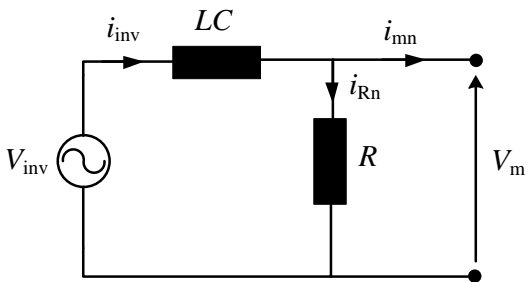

Figure 4. An equivalent single line diagram of the proposed RLC compensator

\subsection{Analysis of the proposed RLC compensator}

The equivalent circuit of $R L C$ compensator connected with a PMSM is shown in Fig. 5. The above equivalent circuit can be simplified using the star-delta conversion method; the new delta impedances are shown in Eqs.(13-15).

$Z_{13}=\frac{Z_{1} Z_{2}+Z_{2} R_{f}+R_{f} Z_{1}}{Z_{2}}$

$Z_{12}=\frac{Z_{1} Z_{2}+Z_{2} R_{f}+R_{f} Z_{1}}{R_{f}}$

$Z_{23}=\frac{Z_{1} Z_{2}+Z_{2} R_{f}+R_{f} Z_{1}}{Z_{1}}$

where $Z_{1}=s L_{f}+\frac{1}{s C_{f}}$ and $Z_{2}=R_{s}+s L_{s}$

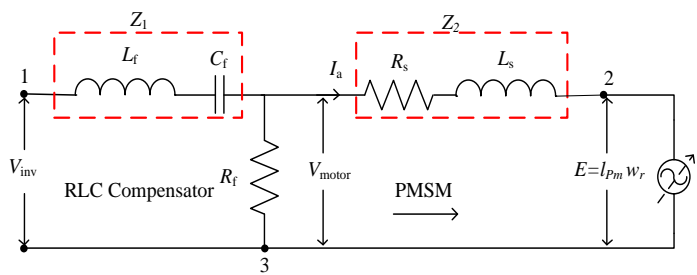

Figure 5. An equivalent circuit of a PMSM with an RLC compensator per phase

The entire transfer function of a PMSM connected with an $R L C$ compensator is obtained as follows:

$$
\begin{aligned}
& E=\frac{V_{i n v}}{Z_{12}+Z_{23}} \times Z_{23} \\
& \left.\therefore T F\right|_{v}=\frac{E}{V_{i n v}}=\frac{Z_{23}}{Z_{12}+Z_{23}}
\end{aligned}
$$

by substituting the amount of $Z_{1}$ and $Z_{2}$ in Eq.(15) and simplifying the new form to be as follows:

$Z_{23}=\frac{n_{1}+n_{2}+n_{2}}{R_{s}+s L_{s}}$

where

$$
n_{1}=R_{f}\left(s L_{f}+\frac{1}{s C_{f}}\right.
$$$$
n_{2}=R_{f}\left(R_{s}+s L_{s}\right)
$$ 
$\therefore Z_{23}=\frac{n_{1}+n_{2}+n_{2}}{s^{2} C_{f} L_{s}+s C_{f} R_{s}}$ and $Z_{12}=\frac{n_{1}+n_{2}+n_{2}}{s C_{f} R_{f}}$ then:

$\left.T F\right|_{v}=\frac{\frac{n_{1}+n_{2}+n_{2}}{s^{2} C_{f} L_{s}+s C_{f} R_{s}}}{\frac{n_{1}+n_{2}+n_{2}}{s C_{f} R_{f}}+\frac{n_{1}+n_{2}+n_{2}}{s^{2} C_{f} L_{s}+s C_{f} R_{s}}}$

$\left.T F\right|_{v}=\frac{s C_{f} R_{f}}{s^{2} C_{f} L_{s}+s\left(C_{f} R_{s}+C_{f} R_{f}\right)}$

$\left.T F\right|_{\text {total }}=\frac{\omega_{r}}{V_{i n v}}=\frac{C_{f} R_{f}}{s C_{f} L_{s} \lambda_{p m}+\left(C_{f} R_{s} \lambda_{p m}+C_{f} R_{f} \lambda_{p m}\right)}$

For stability analysis, the entire transfer function (i.e. the ratio of the rotor speed to the inverter voltage) is determining in Eq. (20) using the parameters listed in Table $\mathbf{1 .}$

$\left.T F\right|_{\text {total }}=\frac{18.2}{5.4 \times 10^{-4} s+3.4}$

The root locus analysis is used to verify the stability of PMSM-Drive system supplied by the inverter via $R L C$ compensator under the variation of rotor speed. Fig. 6 shows the root locus of Eq.(20), which includes a single pole, has the characteristics of (Gain $=0$; Pole $=-6.23 \mathrm{e}^{-3}$; Damping $=1$ and Overshot $=0 \%$ ). It is observed that the system is stable for the optimum values of $R L C$ compensator for $500 \mathrm{rpm}, 1000 \mathrm{rpm}$, and $1500 \mathrm{rpm}$.

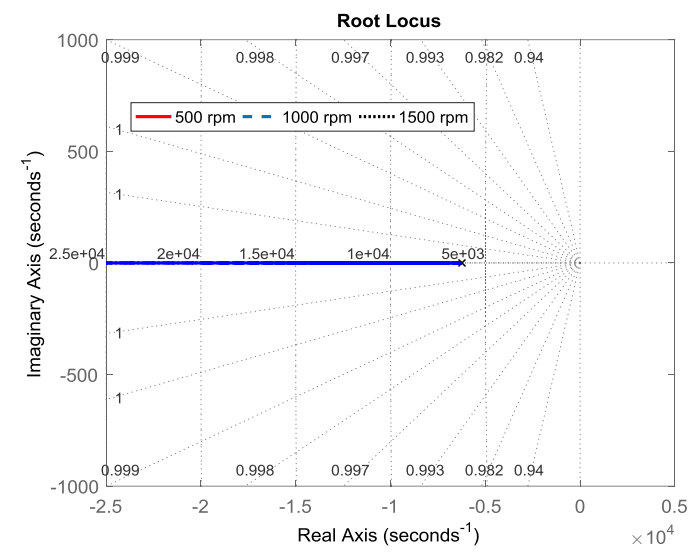

Figure 6. Root locus of the entire transfer function

\section{Simulation Study}

In this Section, the implementation of PMSM-drive system is demonstrated using the simulation parameters listed in Table 1, where $f$ sw is the switching frequency of the inverter. The block diagram of the Simulink model is illustrated in Fig. 7. For performance verification, two scenarios (with and without $R L C$ compensator) are studied which are: (i) at a fixed load and (ii) a step-change in load; under the variation of rotor speed (500-1500) rpm.

Table 1. Parameters of the proposed drive-system

\begin{tabular}{lll}
\hline & PMSM (Surfaced mounted type) Parameters[25] \\
\hline$R_{\mathrm{s}}$ & Stator winding resistance & $2.87 \Omega$ \\
$L_{\mathrm{d}}=L_{\mathrm{q}}$ & Stator inductances in rotary reference & $8.5 \mathrm{mH}$ \\
$\lambda_{\mathrm{m}}$ & frame & $0.175 \mathrm{mWb}$ \\
$J$ & Permanent magnetic flux & $8 \times 10^{-4} \mathrm{~kg} \cdot \mathrm{m}^{2}$ \\
$p$ & Rotor moment of inertia & 2 \\
\hline & Number of pole-pairs & $25 \mathrm{KH}_{\mathrm{z}}$ \\
\hline$f_{\mathrm{sw}}$ & \multicolumn{2}{c}{ RLC compensator Design Parameters } \\
$f_{\mathrm{r}}$ & Switching frequency & $12.5 \mathrm{KH}_{\mathrm{z}}$ \\
$\omega_{1}$ & Resonance frequency & $1.571 \times 10^{5} \mathrm{rad} / \mathrm{sec}$ \\
$\omega_{2}$ & Lower cut-off frequency & $3.665 \times 10^{5} \mathrm{rad} / \mathrm{sec}$ \\
$\mathrm{Q}$ & Upper cut-off frequency & 1.1456 \\
$\mathrm{R}_{\mathrm{f}}$ & Quality factor & $50 \Omega$ \\
$\mathrm{L}_{\mathrm{f}}$ & Compensator resistance & $250 \mu \mathrm{H}$ \\
$\mathrm{C}_{\mathrm{f}}$ & Compensator inductor & $725 \mu \mathrm{F}$ \\
\hline
\end{tabular}

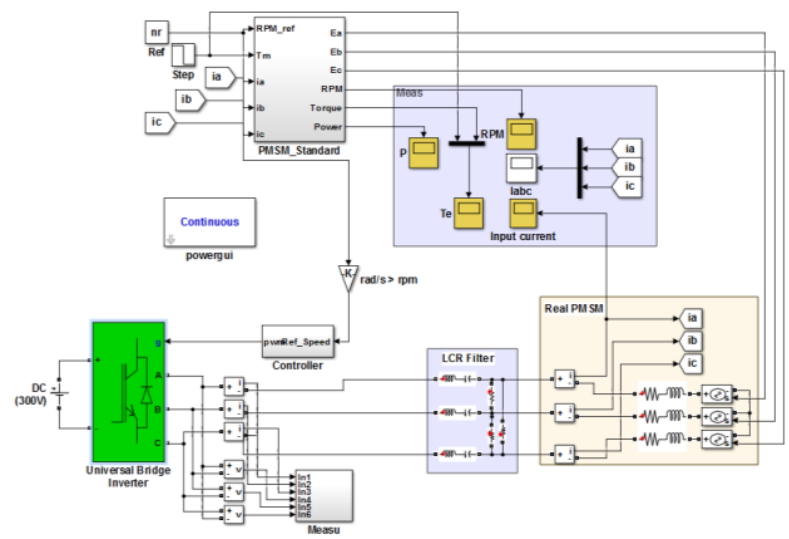

Figure 7. block diagram of the simulation model

\subsection{Results at a Fixed Load}

At full-load, a simulation test and its findings are illustrated in Figures (810). In Figures (8-c,9-c, and 10-c), the electromagnetic torque at steadystate shows the rigid performance of the proposed $R L C$ compensator under the change of rotor speeds (500 rpm, $1000 \mathrm{rpm}$, and $1500 \mathrm{rpm}$ ). It is observed that the steady-state peak-peak torque-ripple in case of without $R L C$ compensator are $(0.150 \mathrm{~N} . \mathrm{m}),(0.154 \mathrm{~N} . \mathrm{m})$ and $(1.162 \mathrm{~N} . \mathrm{m})$ for 500 $\mathrm{rpm}, 1000 \mathrm{rpm}$, and $1500 \mathrm{rpm}$ respectively. While in the case of with the proposed RLC compensator are (0.045 N.m), (0.044 N.m) and (0.040 N.m) for $500 \mathrm{rpm}, 1000 \mathrm{rpm}$, and $1500 \mathrm{rpm}$ respectively. Figures (8-a,9$\mathrm{a}$, and 10-a) show line current waveforms without $R L C$ compensator at $500 \mathrm{rpm}, 1000 \mathrm{rpm}$, and $1500 \mathrm{rpm}$ respectively. It is observed that distortion increased with increasing the rotor speeds and the THD are always above 5\% as listed in Table 2. While Figures (8-b,9-b, and 10-b) show line current waveforms with the proposed $R L C$ compensator at 500 $\mathrm{rpm}, 1000 \mathrm{rpm}$, and $1500 \mathrm{rpm}$ respectively. It is clear that the waveforms are sinusoidal for all rotor speeds and the THD are always less than $1 \%$ as presented in Table 2. 


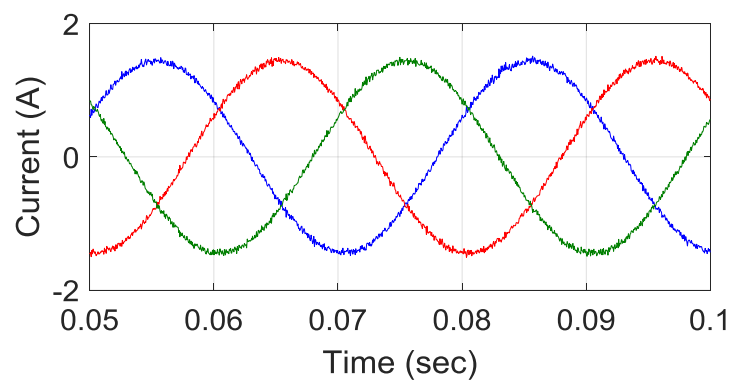

(a) Line currents without RLC compensator

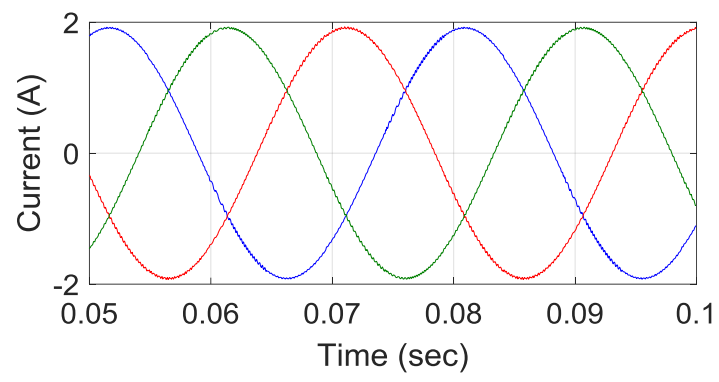

(b) Line currents with RLC compensator

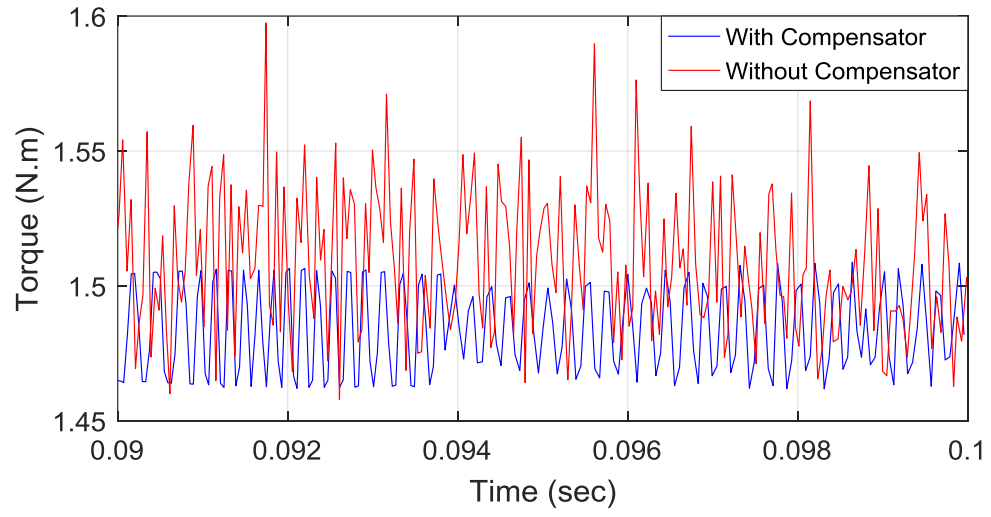

(c) Electromagnetic torque comparison

Figure 8. Simulation results at a fixed load for rotor speed 500rpm

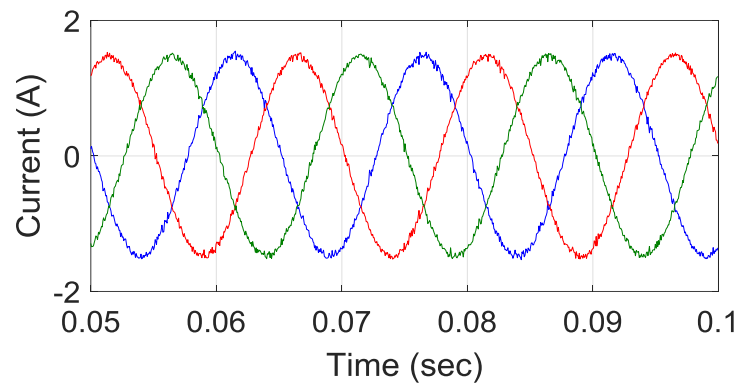

(a) Line currents without RLC compensator

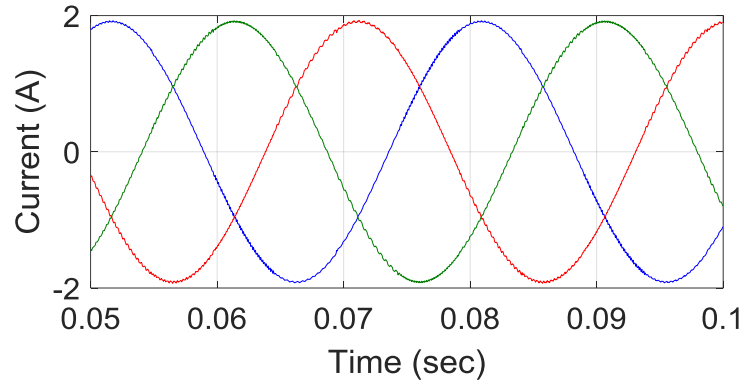

(b) Line currents with RLC compensator

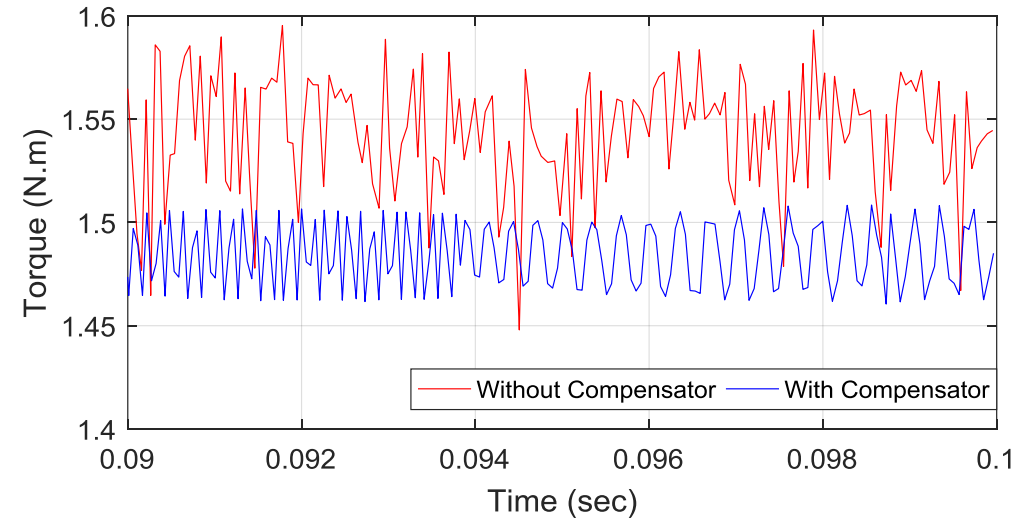

(c) Electromagnetic torque comparison

Figure 9. Simulation results at a fixed load for rotor speed 1000rpm 


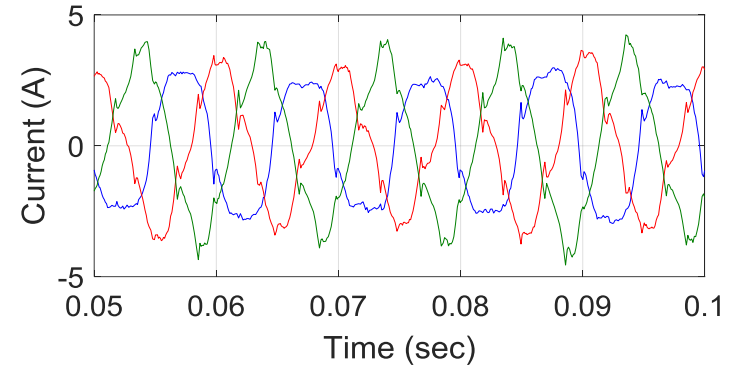

(a) Line currents without RLC compensator

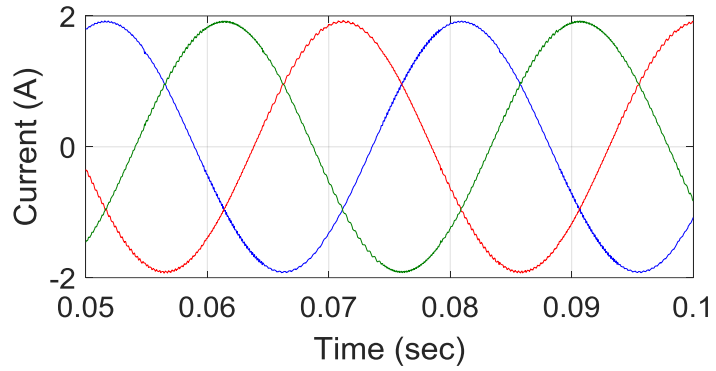

(b) Line currents with RLC compensator

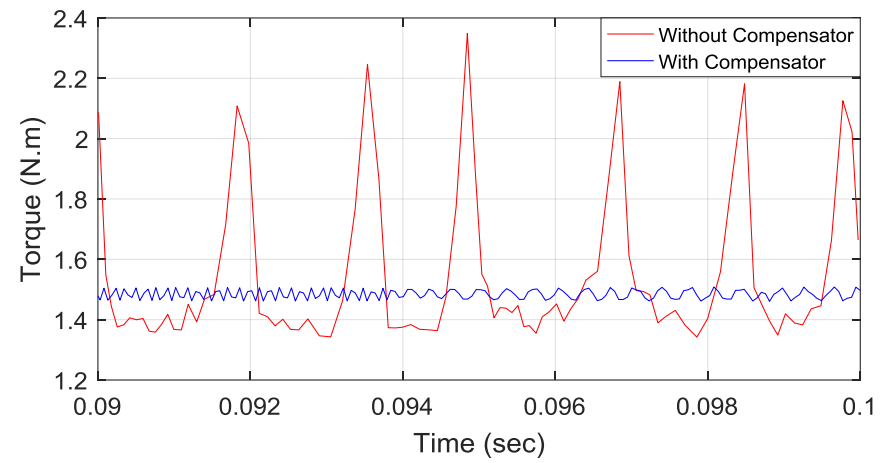

(c) Electromagnetic torque comparison

Figure 10. Simulation results at a fixed load for rotor speed 1500rpm

Table 2. Performance results for various rotor speeds

\begin{tabular}{lllllll}
\hline Rotor Speed(rpm) & & $\mathbf{5 0 0}$ & $\mathbf{7 5 0}$ & $\mathbf{1 0 0 0}$ & $\mathbf{1 2 5 0}$ & $\mathbf{1 5 0 0}$ \\
\hline \multirow{2}{*}{ Torque Ripple } & Without Compensator & $13.34 \%$ & $13.5 \%$ & $14.67 \%$ & $41.33 \%$ & $83.33 \%$ \\
& With Compensator & $3.13 \%$ & $3.20 \%$ & $3.20 \%$ & $3.06 \%$ & $3.13 \%$ \\
\hline \multirow{2}{*}{ Power Ripple } & Without Compensator & $11.71 \%$ & $12.2 \%$ & $15.91 \%$ & $50.92 \%$ & $82.76 \%$ \\
& With Compensator & $2.92 \%$ & $3.26 \%$ & $3.31 \%$ & $3.11 \%$ & $3.09 \%$ \\
\hline \multirow{2}{*}{ Current $T H D$} & Without Compensator & $7.23 \%$ & $7.29 \%$ & $7.81 \%$ & $10.78 \%$ & $18.93 \%$ \\
& With Compensator & $0.77 \%$ & $0.78 \%$ & $0.89 \%$ & $0.67 \%$ & $0.77 \%$ \\
\hline
\end{tabular}

Fig. 11 shows the frequency spectrum vs. THD of the input line current at various rotor speeds with and without $R L C$ compensator. It can be seen that $T H D$ s with $R L C$ compensator are improved in comparison with the previous case study.

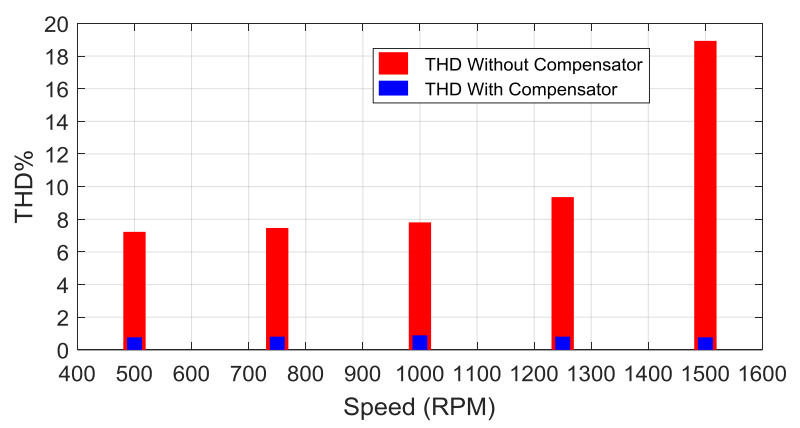

Figure 11. Total harmonic distortion of the input current at a range of rotor speed

\subsection{Results at a Step Change in Load}

To verify the sensitivity of the proposed $R L C$ compensator under the load change from full-load to half-load during $0.1 \mathrm{sec}$. Simulation results are presented in Fig. 12. It can be observed from Table 3 that the percentage increase in torque ripple with respect to full-load are $1.46 \%, 1.67 \%, 1.13 \%$, $0.33 \%$ and $1.6 \%$ at $500 \mathrm{rpm}, 750 \mathrm{rpm}, 1000 \mathrm{rpm}, 1250 \mathrm{rpm}$ and $1500 \mathrm{rpm}$, respectively. These percentages are always less than $2 \%$.

Table 3. Simulation results at a step change in load

\begin{tabular}{lll}
\hline Speed & Ripple Factor & \\
\hline & Full-Load & Half-Load \\
500 & $3.07 \%$ & $4.53 \%$ \\
750 & $3.06 \%$ & $4.73 \%$ \\
1000 & $3.13 \%$ & $4.26 \%$ \\
1250 & $3.80 \%$ & $4.13 \%$ \\
1500 & $2.93 \%$ & $4.53 \%$ \\
\hline
\end{tabular}




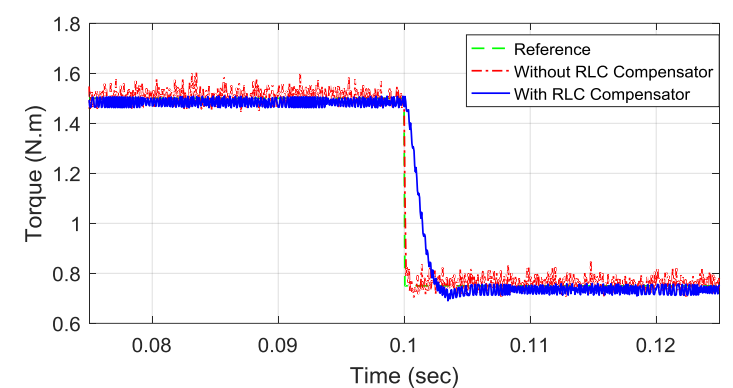

(a) Electromagnetic torque comparison at 500rpm

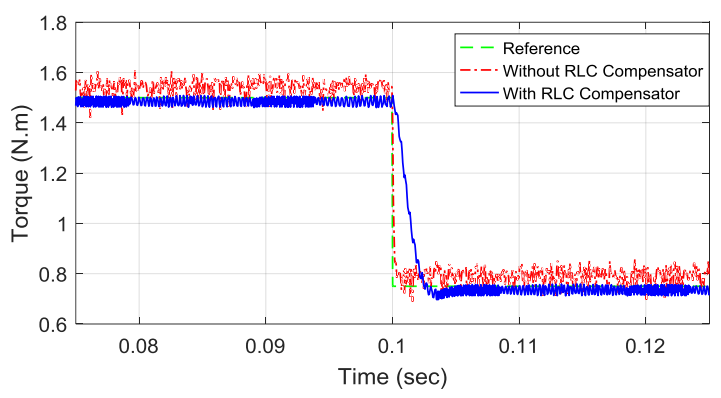

(b) Electromagnetic torque comparison at 1000rpm

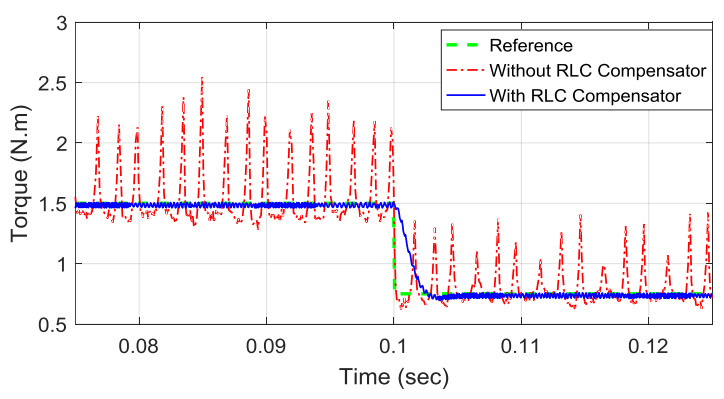

(c) Electromagnetic torque comparison at 1500rpm

Figure 12. Simulation results at a step-change in load

\section{Conclusion}

This paper developed an $R L C$ compensator for a PMSM-drive system to improve its performance, i.e. minimizing the $T H D$ of the line current and ripples in electromagnetic torque. In addition, this paper reviewed the control methods and drive topologies for torque-ripple reduction. The existing control methods for torque-ripple reduction were based on improving the standard vector control using intelligent techniques, which are so sensitive with rotor speed variations. In typical methods, $R L C$ filters have been implemented, which were suitable for fixed-speed drive systems. In this research, an $R L C$ compensator is improved for torque-ripple reduction under a wide range of rotor speeds (500-1500) rpm. The proposed $R L C$ compensator is optimally designed and the stability analysis is verified using the root locus method. The line current of the PMSM with the proposed $R L C$ compensator includes less-oscillations than without $R L C$ compensator, hence reduction of $T H D$ is observed consequently the torqueripple is improved. Results have shown that in case of without $R L C$ compensator, the maximum values of $T H D$ of line current and $R F$ of torque are $18.93 \%$ and $83.33 \%$, respectively. While in the case with the proposed $R L C$ compensator the maximum values of $T H D$ and $R F$ are $0.89 \%$ and $3.20 \%$, respectively.

\section{REFERENCES}

[1] M. Soora, A.Vandhana, V.Srujana, Torque Ripple Minimization of a BLDC Motor Drive by Using Electronic Commutation and Speed, Current Controllers, International journal of Engineering, Business and Management, 1(1) (2017) 1927.

[2] I. Bakhti, S. Chaouch, A. Makouf, T. Daoud, Speed control of permanent magnet synchronous motor using different strategy of sliding mode approach, Journal of Engineering Science and Technology, 12(10) (2017) 2778-2791.

[3] M. Wang, J. Yang, C. Zhu, Hybrid SVPWM technique for reduced torque ripple in permanent magnet synchronous motor, in: 2014 International Power Electronics and Application Conference and Exposition, IEEE, 2014, pp. 12971302.

[4] B.Adhavan, M.S.Birundha, Dr.C.S.Ravichandran, Dr.V.Jagannathan, Torque Ripple Reduction in Permanent Magnet Synchronous Motor using Fuzzy Logic Control, Australian Journal of Basic and Applied Sciences, 7(7) (2013) 61-68.

[5] W. Sibo, Z. Huichao, L. Zhiyu, W. Xiaoxu, A new torque ripple test method based on PMSM torque ripple analysis for electric vehicles, in: EVS28 International Electric Vehicle Symposium and Exhibition, 2015, pp. 1-10.

[6] H.M. Soliman, S. Hakim, Torque ripple minimization suppress harmonics and noise of brushless pm synchronous motors derived by field oriented control, IJRRAS 12, 11(3) (2012).

[7] F. Suja, P.M. Mary, Minimization of torque ripples in permanent magnet synchronous motor-overview, International Journal of Scientific \& Engineering Research, 4 (2013).

[8] E. Espíndola-López, A. Gómez-Espinosa, R. Carrillo-Serrano, J. Jáuregui-Correa, Fourier series learning control for torque ripple minimization in permanent magnet synchronous motors, Applied Sciences, 6(9) (2016) 254.

[9] W. Wang, W. Wang, Compensation for inverter nonlinearity in permanent magnet synchronous motor drive and effect on torsional vibration of electric vehicle driveline, Energies, 11(10) (2018) 2542.

[10] T. TÜRKER, I.O.K. Khudhair, A switched current controller with commutation delay compensation for the reduction of commutation torque ripple in BLDCM drives, Turkish Journal of Electrical Engineering \& Computer Sciences, 25(4) (2017) 2635-2646.

[11] R. Amirthalingam, B. Mahadevan, A new approach for minimizing torque ripple in a BLDC motor drive with a front end IDO dc-dc converter, Turkish Journal of Electrical Engineering \& Computer Sciences, 25(4) (2017) 2910-2921.

[12] B. Tan, Z. Hua, L. Zhang, C. Fang, A New Approach of Minimizing Commutation Torque Ripple for BLDCM, Energies, 10(11) (2017) 1735.

[13] J. Guemes, A. Iraolagoitia, M. Donsion, J. Del Hoyo, Analysis of torque in permanent magnet synchronous motors with fractional slot windings, in: 2008 18th International Conference on Electrical Machines, IEEE, 2008, pp. 1-4.

[14] J. Holtz, L. Springob, Identification and compensation of torque ripple in highprecision permanent magnet motor drives, IEEE Transactions on Industrial Electronics, 43(2) (1996) 309-320.

[15] H. Zhu, X. Xiao, Y. Li, Torque Ripple Reduction of the Torque Predictive Control Scheme for Permanent-Magnet Synchronous Motors, IEEE Transactions on Industrial Electronics, 59(2) (2012) 871-877.

[16] W.Q. Chu, Z.Q. Zhu, Reduction of On-Load Torque Ripples in Permanent Magnet Synchronous Machines by Improved Skewing, IEEE Transactions on Magnetics, 49(7) (2013) 3822-3825.

[17] Z. Weidong, B. Fahimi, S. Pekarek, A field reconstruction method for optimal excitation of permanent magnet synchronous machines, IEEE Transactions on Energy Conversion, 21(2) (2006) 305-313.

[18] H. Fadil, D. Yousfi, M.L. Elhafyani, Y.A. Driss, A.R. Nasrudin, Four-switch three-phase PMSM converter with output voltage balance and DC-link voltage offset suppression, in: 2016 International Conference on Electrical Sciences and Technologies in Maghreb (CISTEM), 2016, pp. 1-7.

[19] J. Wang, W.C. Gan, L. Qiu, A gain scheduled controller for sinusoidal ripple elimination of AC PM motor systems, in: 2007 Mediterranean Conference on Control \& Automation, 2007, pp. 1-6.

[20] K. Hatua, A.K. Jain, D. Banerjee, V.T. Ranganathan, Active damping of output LC Filter resonance for Vector-Controlled VSI-Fed AC Motor Drives, IEEE Transactions on Industrial Electronics, 59(1) (2012) 334-342.

[21] G. Zhang, X. Liu, L. Mei, H. Ouyang, X. Deng, Filter design at the output of the inverter in PMSM drives, COMPEL - The international journal for computation and mathematics in electrical and electronic engineering, 36(1) (2017) 364-377.

[22] M. Said-Romdhane, M. Naouar, I. Belkhodja, E. Monmasson, An Improved LCL 
Filter Design in Order to Ensure Stability without Damping and Despite Large Grid Impedance Variations, Energies, 10(3) (2017) 336.

[23] H. Horowitz, in: chapter 6, pp. 32-60.

[24] J. Arrillaga, N.R. Watson, POWER SYSTEM HARMONICS, John Wiley \& Sons, 2003.

[25] I. Yousefi, M. Ghanbari, Parameter Estimation of Permanent Magnet Synchronous Motor Using Orthogonal Projection and Recursive Least Squares Combinatorial Algorithm, Mathematical Problems in Engineering, 2015 (2015) 7. 